\title{
Ekonomik Büyüme ve Dış Ticaretin Çevre Kirliliği Üzerindeki Etkisi: Türkiye İçin Bir ARDL Sınır Testi Yaklaşımı
}

\author{
Doç. Dr. Murat ÇETÍN

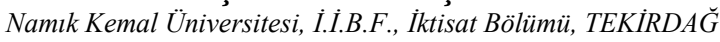 \\ Yrd. Doç. Dr. Fahri SEKER \\ Bozok Üniversitesi, İ.I.B.F., Iktisat Bölümü, YOZGAT
}

\begin{abstract}
$\ddot{O Z Z E T}$
Bu çalışma, Türkiye'de ekonomik büyüme ve dış ticaretin çevre kirliliği üzerindeki etkisini karbondioksit salınımı verilerini kullanarak inceler. Burada, Pesaran vd. tarafindan son zamanda gelişstirilmiş olan ARDL sınır testi yaklaşımı 1980-2010 dönemi için kullanılmışıı. Test sonuçları, 1.520 ve 0.265 elastikiyet değerleri ile değişkenler arasında uzun dönemli bir iliş̧kinin varlığını göstermektedir. Başka bir ifadeyle, ekonomik büyüme ve dış ticaret açıklığ uzun dönemde çevresel kirliliği artırmaktadır. Sonuç olarak Türkiye'nin İklim Değişikliği Ulusal Eylem Planı 2011-2023 çerçevesinde karbondioksit azaltma hedeflerini gerçekleştirebilmesi için çevre politikalarını tekrar gözden geçirmesi gereklidir.
\end{abstract}

Anahtar Kelimeler: Ekonomik büyüme, Dlş ticaret, Çevre kirliliği, ARDL sınır testi.

JEL Sinıflaması: C32, F18, O44, Q56

The Impact of Economic Growth and Foreign Trade on The Environmental Pollution: An ARDL Bounds Testing Approach for Turkey

ABSTRACT

This paper examines the impact of economic growth and foreign trade on the environmental pollution as measured by carbon dioxide emissions in Turkey. Here, we use the ARDL bounds testing approach recently developed by Pesaran et al. over the time period 19802010. The results suggest that there is a long-run relationship between variables with the estimated elasticities of 1.520 and 0.265 , respectively. In other words, economic growth and trade openness increase environmental pollution in the long run. The main conclusion of this paper is that in order to fulfill National Climate Change Action Plan 2011-2023 to reduce carbon dioxide emissions, Turkey needs a revised environmental policy.

Key Words: Economic growth, Foreign trade, Environmental pollution, ARDL bounds testing.

JEL Classifications: C32, F18, O44, Q56

\section{Giriş}

Ekonomik büyüme, diş ticaret ve çevre kirliliği arasındaki ilişki genel olarak Çevresel Kuznets Eğrisi (ÇKE) çerçevesinde ele alınmaktadır. Bu argümana göre kişi başına gelir ile çevre kirliliği arasında ters-U şeklinde bir ilişki vardır (Grossman ve Krueger, 1993 ve 1995). ÇKE'nin bulgularına göre, üretim artışının ortaya çıkardığı kirlilik, belli bir gelir seviyesinden sonra azalma eğilimine girecektir. Nitekim bu görüşü destekleyen çeşitli ampirik araştırmalar yapılmıştır (Selden ve Song, 1994; Vincent, 1997; Gale ve Mendez, 1998). Ancak bu bulgulara şüpheyle yaklaşan çalışmalara göre gelişmiş ülkelerdeki gelir artış1 
ile birlikte kirlilik düzeyinin azalması, küresel ölçekte çok fazla anlamlı değildir. Çünkü gelişmiş ülkeler kirlilik yoğun endüstrileri gelişmekte olan ülkelere kaydırmak suretiyle kendi ülkelerindeki sera gazı salınımını azaltmakta ve fakat küresel ölçekte çevresel bir iyileşme olmamaktadır. Bu nedenle ÇKE hipotezinin küresel ölçekte geçerliliği konusunda ciddi bir belirsizlik vardır (Galeotti $v d$., 2009). Özellikle sera gazı olarak karbondioksit salınımının neden olduğu sıcaklık artışı ve iklim değişikliği küresel etkiye sahip olduğu için ortaya çıkan negatif dışsallıkların içselleştirilmesi ve sosyal maliyetlerin de küresel ölçekte paylaşılması gerekmektedir. Oysa bedavacılık (free-riding) nedeniyle özellikle gelişmiş ülkeler bu sorumluluğu üstlenmekte çekimser davranmaktadırlar (He ve Richard 2010: 1083). Örneğin Amerika Birleşik Devletleri, tarihsel olarak küresel hava kirliliğinin en büyük sorumlusu olmasına rağmen kirliliğin azaltılmasına yönelik uluslararası girişimlere destek olma konusunda (Kyoto görüşmelerinde olduğu gibi) çekimserliğini sürdürmektedir.

Diğer taraftan Palmer ve Simpson (1993), Cole $v d$. (2004) gibi bazı araştırmacılar kirlilik sığınağı veya ekolojik damping olarak ifade edilen hipotezlere dikkati çekerek ÇKE çalışmalarında ticaretin öneminin vurgulanması gerektiğini belirtirler. Ayrıca etkili bir argüman olarak son yıllarda tartışılan ve "dipte rekabet (race the bottom)" olarak ifade edilen görüşe göre ülkeler, küresel rekabet nedeniyle, diş ticarette dezavantaj getirecek çevresel yasal düzenlemeler yapmaktan kaçınmaktadırlar. Bu nedenle küresel anlamda en alt düzeyde başka bir ifadeyle çevreye duyarlı düzenlemelerin olmadığı bir serbest piyasa ortamında ticaret gerçekleşmektedir (Lapan ve Sikdar, 2011: 3). Bu yaklaşım doğal olarak çevre kirliliğine ve doğal kaynakların sürdürülemez bir şekilde tüketilmesine yol açmaktadır.

Ortodoks iktisadın savunduğu ve daha çok serbest piyasa ve kendiliğinden denge varsayımlarına dayanan görüşlerin karşısında eleştirel yaklaşımların ortaya çıkardığı şüpheler üzerine, dış ticaretin çevre üzerindeki etkilerini araştırmak için mikro düzeyde girdi-çıktı ve ayrıştırma (decomposition) analizleri kullanılmaya başlanılmıştır. Bu çalışmalara göre diş ticaret üç farklı şekilde çevre üzerinde etkili olmaktadır: Ölçek, teknoloji ve kompozisyon etkisi. Ölçek etkisi, ticaret ile birlikte piyasaların genişlemesi ve buna bağlı olarak üretim ve tüketim artışının, kirlilik seviyesini yükseltebileceğini ifade eder. Teknik etki, ticaretin daha gelişmiş üretim tekniklerine ve çevresel düzenlemelere imkân sunması nedeniyle daha temiz teknolojilere ya da üretim süreçlerine geçilmesinden kaynaklanan olumlu bir etki oluşturur. Kompozisyon etkisi, uzmanlaşmanın neden olduğu üretim alanındaki değişmelerden kaynaklanır. Bu argümanda, ticareti yapılan malların kompozisyonu üzerinde durulmakta ve ticaretin kirlilik üzerinde pozitif ve negatif olmak üzere iki yönlü etki yapabileceği ileri sürülmektedir. $\mathrm{Bu}$ ters yönlü etkilerin farklı özellikleri dolayısıyla ticaretin çevre üzerindeki nihai etkisini tespit etmek oldukça güçtür (Cole $v d$., 2004).

Netice olarak ekonomik büyüme ve serbest dış ticaretin çevre üzerindeki etkileri hakkında tüm ülkeler için geçerli olacak bir sonuca ulaşmak oldukça güç 
görünmektedir. $\mathrm{Bu}$ nedenle ülke bazında çalışmalar ön plana çıkmaktadır. Büyümenin ve dış ticaretin çevre üzerindeki etkilerini araştırmak, son on yılda ortalama yıllık \% 5 büyüme ve toplam \% 437 oranında dış ticaret hacmindeki artış ile Türkiye ekonomisi için özel bir öneme sahiptir. Gelir ve dış ticaretteki artışa paralel olarak Türkiye'nin karbondioksit salınımı 1990 yılında 141 milyon ton $\mathrm{CO}_{2}$ salınımı 2011 yılında 344 milyon tona ulaşarak yaklaşık \% 244 gibi yüksek bir artış göstermiştir (TUIK, 2013). 2012 yılı itibariyle Türkiye'nin kişi başına karbondioksit salınımı dünya ortalamasının altında olmasına rağmen kirlilik artış hızı nedeniyle hem akademik hem de politik çevrelerde ilgi odağ olmaya devam etmektedir (ÇŞB, 2011: 6).

Türkiye, ekonomik büyümenin önünde engel olacağ 1 ve yasal düzenlemeler nedeniyle rekabet gücünün zayıflayacağı endişesi ile Ek-1 listesinde yer alıp, Kyoto protokolüne göre karbondioksit salınımını indirme yükümlülüğü altına girmeyen tek ülke konumundadır. Ancak Avrupa Birliği’ne aday bir ülke olarak Türkiye'nin çevre kirliğini azaltmaya yönelik yükümlülükleri bulunmaktadır. Daha temiz bir çevre ve sera gazları salınımlarının azaltılması konusunda uluslararası baskıların giderek artacağını düşünürsek, Türkiye'nin bir taraftan dış ticaret odaklı büyüme politikalarına devam ederken, diğer taraftan dış ticareti ve büyümeyi dışlamayacak başka bir ifadeyle büyüme politikaları ile uyumlu bir çevre politikası geliştirmek zorundadır.

Bu çalışmada, 1980-2010 döneminde Türkiye ekonomisinde ekonomik büyüme ve dış ticaretin çevre kirliliği üzerindeki etkisi karbondioksit salınımı dikkate alınarak araştırılacaktır. Türkiye çevre endeksi hesaplamalarında 44,80 endeks puanı ile ülkeler sıralamasında oldukça gerilerde sayılabilecek 109. sırada yer almaktadır (EPI, 2013). Diğer taraftan Türkiye petrol ürünlerinde yüksek vergi oranlarına sahip olmasına rağmen sera gazı salınım miktarı çok hızlı bir şekilde artmaya devam etmektedir (OECD, 2012: 27).

Çalışmada çevre kirletici etken olarak sadece karbondioksit gazı verileri kullanılmıştır. Çünkü Türkiye için 2011 yılı itibari ile yaklaşık toplam 422 milyon ton sera gazının 344 milyon tonu $\mathrm{CO}_{2}$ salınımından kaynaklanmaktadır (TÜIK, 2013). Bu nedenle küresel 1sınma tehlikesinin çözümünde en etkili politika, karbondioksit salınımının azaltılması olduğu düşünülmektedir.

Diğer taraftan tek bir ülke üzerinde ampirik bir inceleme yapmanın çeşitli avantajları da bulunmaktadır. Özellikle ülkelerin kendine özgü şartları dikkate alınarak, daha uygulanabilir politika önerileri mümkün olmaktadır. Ayrıca, göreceli olarak yeni bir ekonometrik yöntem olan ARDL sınır testi yaklaşımı ile gelişmekte olan ülkeler bağlamında ek kanıtlar ortaya koyabilmek ve literatürün gelişmesine katkı sağlayabilmek çalışmanın önemli amaçları olacaktır.

Çalışmanın bundan sonraki bölümleri şu şekilde ele alınmıştır: İkinci bölümde, teorik ve ampirik literatür incelenmiştir. Üçüncü bölümde çalışmada kullanılan model, veri seti ve tahmin yöntemleri açıklanmıştır. Dördüncü ve beşinci bölümde, ekonometrik metodoloji ve ampirik bulgular ele alınmıştır. Sonuç bölümünde ise ampirik analizlerden elde edilen sonuçlar değerlendirilerek politika çıkarımlarında bulunulmuştur. 


\section{Literatür}

Gelir ve ticaret liberalleşmesinin çevre üzerindeki etkisi son y1llarda çevresel tehditlerin giderek artması nedeniyle ekonomi literatüründe önemli bir araştırma konusu olmaya devam etmektedir. Bu tartışma, aslında 1970'li yılların başına kadar uzanmaktadır. Meadows $v d$., (1972) çalışmalarında hangi tür doğal kaynakların sürdürülebilir büyüme ile uyumlu olabileceğini sorgulamıştır. Victor (1972) ekonomik faaliyetlerin girdi olarak çevresel kaynakları kullanması ve çevrenin massetme kapasitesinin aşılması durumunda büyümenin çevre için bir tehdit oluşturabileceğini belirtmiştir. Beckerman (1974) kaynak kıtllğı nedeniyle büyümenin sınırlarının önemli bir sorun olduğunu ssrarlı bir şekilde savunmuştur. Arrow vd., (1995)'e göre, ekonomik büyüme ve liberalleşmeyi destekleyici politika reformlarının en temel riski çevresel sonuçların pek fazla dikkate alınmayışıdır. Bu tutum, özellikle de gelişmekte olan ülkelerin geleceğe yönelik sürdürülebilir gelişmelerini tehlikeye sokabilecek ciddi çevresel problemlerin doğmasına neden olabilmektedir.

Çevresel Kuznets Eğrisi 1990'ların başlarında Grossman \& Krueger (1991)'ın “NAFTA'nın Potansiyel Çevresel Etkileri” adlı çalışmasıyla ilk olarak ortaya çıkmış ve popüler olmaya başlamıştır. Bu çalışmayı Shafik \& Bandyopadhyay (1992)'ın hazırladığı Dünya Bankası Raporu izlemiştir. Bu iki çalışma ÇKE ile ilgili ilk araştırmalar olup ÇKE üzerinde yoğunlaşacak olan bir literatür grubunun doğmasına zemin hazırlamıştır. Nitekim, Grossman \& Krueger (1991), Shafik \& Bandyopadhyay (1992)'yı takiben Panayotou (1993), Selden \& Song (1994), Grossman \& Krueger (1993; 1995), de Bruyn vd., (1998), Suri \& Chapman (1998), Schmalensee vd., (1998), Galeotti \& Lanze (1999), Sachs vd., (1999) ve Vollebergh vd., (2005) ÇKE'nin varlığını kanitlayan deliller sunmuşlardır. Grossman \& Krueger (1993) 42 ülkeye ilişkin hava kalitesi panel verilerini kullanarak bazı hava kalitesi ölçütleri ile kişi başına gelir düzeyi arasında ters-U şeklinde bir ilişkinin varlığını tespit etmişlerdir. Başlangıçta kirlilik düzeyi artmakta, belirli bir gelir düzeyinden sonra ise azalmaktadır. Selden \& Song (1994) sülfürdioksit verilerini kullanarak benzer sonuçlara ulaşmışlardır. Grossman \& Krueger (1995), Shafik \& Banyopadhyay (1992) kirli içme suyu ile ilgili olarak kişi başına gelir ile birlikte kirliliğin azalma eğilimi gösterdiğini, karbon salınımı ile ilgili olarak kişi başına gelir düzeyi ile birlikte kirliliğin arttığını belirlemişlerdir. Giles \& Mosk (2003) Yeni Zelanda ekonomisi için metan gazı salınımı ile kişi başına gelir arasındaki ilişkiyi ve ters-U şeklinde bir eğrinin varlığını göstermişlerdir. Hung ve Shaw (2006) 1988-1997 döneminde Tayvan ekonomisinden nitrik oksit ve karbon monoksit için ÇKE'nin varlığını belirlemişlerdir.

Diğer taraftan Kaufmann $v d$. (1998), Roca $v d$., (2001) ve Meyer $v d$., (2003) ÇKE aleyhine deliller sunmuşlardır. Kaufmann vd., (1998)'e göre karbondioksit ve gelir arasındaki ilişki U şeklinde tespit edilmiştir. Roca $v d$., (2001) İspanya ekonomisinde altı atmosferik kirletici için analiz yapmış, karbondioksit hariç diğer tüm kirlilik göstergelerinde ÇKE hipotezinin geçerli olmadığı sonucuna varmışlardır. Meyer $v d$., (2003) 117 ülkenin verilerine dayalı 
olarak gerçekleştirdiği ve 1990-2000 periyodunu kapsayan çalışmasında değişkenler arasındaki ilişkinin $\mathrm{U}$ şeklinde bir eğriyi desteklediğini kanıtlamışlardır.

Gelir ile çevre arasındaki ilişkiyi inceleyen ampirik çalışmalara eleştirel açıdan yaklaşan Stern $v d$. (1996) farklı ülkelerin verilerinde yer alan diğer değişkenlerin çevre kirliliği ve gelir arasındaki ilişkiyi etkileyebileceğine vurgu yapar. Coondoo ve Dinda (2002) çevre kirliliği-gelir ilişkisinin bir grup ülkeden diğerine değişebileceğini söyler. De Bruyn (1997) ise ülkeler arasındaki yapısal değişmelerin çevre kirliliği ile gelir arasındaki nedensellik ilişkisini etkileyebileceğine işaret eder.

Ekonomik büyümenin yanı sıra çevre kirliliğinin belirleyicisi olarak diş ticaret yoğunluğu değişkeni de kullanılmaktadır. Grossman ve Krueger (1993) dış ticaret ve çevre ilişkisine yönelik geniş bir bakış açısı sergilemişlerdir. Büyümeçevre ilişkisine benzer şekilde ticaret ve yabancı yatırımların liberalleşmesinin çevre kalitesini nasıl etkileyeceğini açıklayabilmek için ölçek etkisi, kompozisyon etkisi ve teknik etki üzerinde durmuşlardır. Lopez (1994), Antweiler vd. (2001) ve Cole $v d$. (2004) ekonomik büyüme, ticaret liberalleşmesi ve doğrudan yabanc1 yatırımların çevre üzerindeki etkileri konusunda önemli açıklamalar getirerek bu yapıyı daha da geliştirmişlerdir. Copeland ve Taylor (1994) statik, gelir düzeyleri farklı iki ülkeli genel denge modelini kullanarak ulusal gelir, kirlilik ve ticaret arasındaki ilişkileri analiz etmişlerdir. Dinamik, iki sektörlü ticaret modelinde Copeland ve Taylor (1997) çevre kalitesi ve reel gelir azalırken, belirli koşullarda serbest ticaretin kirliliği artıracağını göstermiş, böylece ticaret-sürükleyici çevresel bozulma hipotezinin varlığını doğrulamışlardır.

Bazı yazarlar kirlilik sığınağı ya da ekolojik damping hipotezleri gibi hipotezler nedeniyle ÇKE çalışmalarında ticaretin dışlanmaması gerektiğini 1srarla vurgularlar. Ticaretin çevre üzerindeki etkileri ile ilgili ampirik çalışmaların büyük bir kısmı bir biriyle çelişkili sonuçlara ulaşmışlardır. Diğer taraftan (Koo, 1974; Birdsall ve Wheeler, 1993; Lucas vd., 1992; Wheeler ve Martin 1992; Rock 1996; Koo, 1974) ABD’nin girdi/çıtı verilerini kullanarak ticaretin beş temel hava kirletici madde üzerindeki etkilerini araştırmak için basit bir lineer model kullanmıştır. Sonuçlar, ticaret yapan ülkelerin kirlilik düzeylerinin değiştiğini göstermektedir. Bu, ticaret yapan ülkelerin kirlilik düzeyi üzerinde ticaretin doğrudan ve dolaylı etkilerinin olduğunu ortaya koymaktadır. Birdsall ve Wheeler (1992), Lucas $v d$., (1992), Wheeler ve Martin (1992) daha fazla dişa açık politikalar izleyen ülkeler için üretimin kirlilik yoğunluğunda daha düşük büyüme oranlarını tespit etmişlerdir. Rock (1996) bunun aksini iddia etmiş, içe dönük ticaret politikalarıyla karşılaştırıldığında dışa dönük ticaret politikalarının daha fazla kirlilik yoğunluğunu artırdığını göstermiştir.

Suri ve Chapman (1998) ticaret faktörünü GSYIH içinde ihracatın ve ithalatın payı olarak iki kısma ayırarak çevre üzerindeki etkisini araştırmıştır. Ampirik bulgular daha yüksek ihracat payının daha fazla salınıma neden olduğu, daha yüksek ithalat payının ise daha düşük salınım ürettiği sonucuna varmıştır. 
Antweiler vd., (2001) ticaret liberalleşmesinin kirliliği azalttı̆̆ını, Dasgupta $v d$. (2002) ise ticaret liberalleşmesinin kirliliği artırdığını kanıtlamıştır.

Copeland ve Taylor (1995) serbest ticaret, uluslararası gelir transferi ve sınır ötesi çevresel düzenlemelerin refah ve kirlilik düzeyini nasıl etkilediğini teorik olarak incelemiştir. Ülkeler arasındaki farklı gelir düzeyleri ile birlikte serbest ticaretin dünya kirliliğini artıracağını ortaya koymuştur. Copeland ve Taylor (2001) ayrıca, ileri düzeyde çevre ve ticaret politikası analizi için temel oluşturabilecek bir genel denge modeli geliştirmiştir. Model, Hecksher-Ohlin diş ticaret modeli ile Copeland ve Taylor (1994) kirlilik sığınağı modelini baz alır. Bu sistem, büyüme ve ticaret liberalleşmesinin çevresel sonuçlarını ve ülkeler arasındaki stratejik etkileşimleri inceleyebilme imkânı sunar.

Son yıllarda bazı ampirik çalışmalar ticaret, gelir ve çevre arasındaki uzun dönemli ilişkiyi dikkate almıştır. Mete $v d$., (2007) gelişmekte olan ülkelerde dış ticaret yoğunluğunun çevre kirliliği üzerindeki etkisini araştırmışlardır. Regresyon analizlerinin gerçekleştirildiği bu çalışmanın ampirik bulguları Nijerya ekonomisi için ticaret yoğunluğu, $\mathrm{km}^{2}$ başına düşen gelir ve GSYIH'nın, çevresel bozulma ile pozitif ilişki içinde olduğunu kanıtlar niteliktedir. Baek vd. (2009) ticaret, gelir ve sülfürdioksit salınımı arasındaki dinamik etkileşimleri incelemişlerdir. Çalışmanın bulgularına göre gelişmiş ekonomilerde ticaret ve gelir büyümesi çevre kalitesi üzerinde pozitif bir etkiye sahip iken gelişmekte olan ülkelerde negatif bir etki yaratmaktadır. Ayrıca Kukla-Gryz (2009) iki faktörlü yapısal eşitlik modelini kullanarak ekonomik büyüme ve dış ticaretin hava kirliliği üzerindeki etkisini 1995 ve 2000 yılları için analiz etmiştir. Tahmin sonuçları, gelişmekte olan ülkelerde uluslararası ticaret ve kişi başına gelir düzeyinin ekonomik faaliyetlerin yapısında değişmelere neden olduğunu, bunun sonucu olarak hava kirliliğinde bir artışın yaşandığını ortaya koymaktadır. Ayrıca, kişi başına gelirin hava kirliliği yoğunluğu üzerindeki etkisinin gelişmekte olan ve gelişmiş ülkeler arasında değiştiği tespit edilmiştir. Bu etki, gelişmekte olan ülkelerde ekonomik faaliyetlerin yapısının değişmesiyle ortaya çıkar. Boulatoff ve Jenkins (2010) gelir, ticaret ve çevre kalitesi arasındaki dinamik ilişkileri analiz etmişlerdir. Bu çalışmada G7, BRIC, orta ve düşük gelirli ülkelere ilişkin 19802006 dönemi zaman serileri ve panel seriler kullanılmıştır. Johansen test sonuçları, sadece iki ülkede gelir, ticaret ve karbondioksit salınımı arasında bir eşbütünleşme ilişkisi tespit etmiştir. Pedroni test sonuçları ise uzun dönemde gelir, ticaret ve karbondioksit salınımı arasında bir eşbütünleşme ilişkisinin varlığını desteklemektedir.

Son olarak, Türkiye ekonomisi için yapılan önde gelen çalışmaları özetleyebiliriz. Soytas ve Sarı (2009) Türkiye ekonomisi bağlamında 1960-2000 dönemine ilişkin ekonomik büyüme, enerji tüketimi ve karbon dioksit salınımı arasındaki uzun dönemli Granger nedenselliğini test etmiş̧lerdir. Toda-Yamamoto test sonuçları, ekonomik büyüme ve enerji tüketiminden karbon dioksit salınımına doğru işleyen bir nedensellik tespit edememiştir. Halıcıoğlu (2009) Türkiye ekonomisinin 1960-2005 dönemi yıllık verilerini kullanarak karbon salınımı, enerji tüketimi, gelir ve diş ticaret arasındaki dinamik nedensel ilişkileri ampirik 
olarak araştırır. ARDL sınır testi eşbütünleşme sonuçları, değişkenler arasında uzun dönem ilişkisi belirlemiştir. Bu sonuca göre karbon salınımı enerji tüketimi, gelir ve dış ticaret tarafından belirlenmektedir. Öztürk ve Acaravcı (2010) ekonomik büyüme, karbon salınımı, enerji tüketimi ve istihdam arasındaki uzun dönem ve nedensellik ilişkisini ARDL sınır testi yaklaşımıyla Türkiye ekonomisi bağlamında analiz etmişlerdir. 1968-2005 dönemine ilişkin ampirik sonuçlar, Türkiye ekonomisinde değişkenler arasında bir uzun dönem ilişkisinin varlığına işaret etmektedir.

Türkiye ekonomisi bağlamındaki çalışmalardan Halıcıoğlu (2009) genel olarak enerji tüketimi, ekonomik büyüme ve diş ticaretin karbon salınımı üzerindeki etkileri ile ÇKE hipotezinin geçerliliği (başka bir ifadeyle kişi başına gelir ve gelirin karesi değişkenlerinin karbon salınımı üzerinde sırasıyla pozitif ve negatif bir etkiye sahip olup olmadığını) sorgulamıştır. Öztürk ve Acaravcı (2010) ise istihdam, karbon salınımı ve enerji tüketiminin ekonomik büyüme üzerindeki etkilerine yoğunlaşmışlardır. Enerji tüketimi ilk çalışmada karbon salınımının ikinci çalışmada ise ekonomik büyümenin bir belirleyicisi olarak modellenmiştir. Çalışmamızda ise ekonomik büyüme ve diş ticaretin karbon salınımı üzerindeki etkileri analiz edilmektedir. Dolayısıyla kullanılan ampirik model diğer iki çalışmanın modellerinden farklılık arz etmektedir. Ayrıca burada söz konusu değişkenler arasında bir eşbütünleşme ve nedensellik ilişkisinin olup olmadığ1 1980-2010 dönemi itibariyle analiz edilmeye çalışılmıştır. 1980’li yılların başlarının Türkiye ekonomisinde bir yapısal dönüşüme sahne olması nedeniyle 1980-2010 dönemi ampirik analiz dönemi olarak uygun bulunmuştur. Halıcıoğlu (2009)'nun çalışmasına benzer şekilde burada ekonomik büyüme ve dış ticaretin karbon salınımı üzerindeki etkisi pozitif olarak tespit edilmiş ve en önemli karbon salınımı belirleyicisinin ekonomik büyüme olduğu kanısına varılmıştır. Ancak, çalışmamızın ampirik bulgularına göre karbon salınımının dış ticaret elastikiyet değeri daha güçlüdür.

\section{Model ve Veri Seti}

$\mathrm{Bu}$ çalışma, ekonomik büyüme ve diş ticaretin çevre kirliliği üzerindeki etkisini Türkiye ekonomisi bağlamında araştırır. Veri seti 1980-2010 dönemi yıllık verilerini temsil eden 31 gözlemden oluşur. Söz konusu periyod verilerin özellikle de çevre kirliliği ölçütünün elde edilebilirliği dikkate alınarak belirlenmiştir. Çalışmada, aşağıdaki gibi bir lineer tahmin denklemi oluşturulmuştur:

$$
\ln C O_{2}=\beta_{0}+\beta_{1} \ln G D P+\beta_{2} \ln T R A D E+\varepsilon_{t}
$$

Chebbi $v d$., (2009), Boulatoff ve Jenkins (2010) ve Sabori (2012) tarafından kullanılan modeller çalışmanın tahmin denkleminin belirlenmesinde yol gösterici olmuştur. Literatürde sülfür dioksit $\left(\mathrm{SO}_{2}\right)$ ve karbon dioksit $\left(\mathrm{CO}_{2}\right)$ değişkenleri yaygın bir biçimde kullanılmıştır. $\mathrm{Bu}$ çalışmada bireysel ülke analizimizde çevre kirliliği ölçütü olarak karbon dioksit salınımı (metrik ton, kişi başına) değişkeni kullanılmıştır. Ayrıca, ekonomik büyüme ölçütü olarak 2000 baz yılına göre $\$$ fiyatlarıyla hesaplanmış kişi başına GSYİH değişkeni kullanılmıştır. Dış ticareti temsilen dış ticaret açıklığı değişkeni belirlenmiş olup, 
ihracat ve ithalat toplamının GSYİH içindeki payı olarak hesaplanmıştır. (Mete, 2007; Halıcıoğlu, 2009; He ve Patrick, 2010; Öztürk ve Acaravc1, 2010) Çalışmada kullanılan tüm değişkenlere ait bilgiler Tablo 1'de özetlenmiştir. Ayrıca tüm seriler logaritmik forma dönüştürülmüştür. Şekil 1, serilerin grafiksel görünümünü ortaya koymaktadır. Şekil 1'den görüleceği üzere kişi başına gelir, karbon dioksit salınımı ve dış ticaret yoğunluğu değişkenleri zaman içinde birlikte hareket etme eğilimi sergilemektedir.

Tablo 1: Verilerin Tanımlanması

\begin{tabular}{|c|c|c|}
\hline Değişkenler & Açıklama & Kaynak \\
\hline $\ln C O_{2}$ & $\mathrm{CO}_{2}$ salınımı (metrik ton, kişi başına) & Dünya Bankası \\
\hline $\ln G D P$ & Kişi başına GSYİH (sabit, 2000\$) & Dünya Bankası \\
\hline $\ln T R A D E$ & Dış ticaret yoğunluğu (İhracat+İthalat/GSYİH) & Dünya Bankası \\
\hline
\end{tabular}
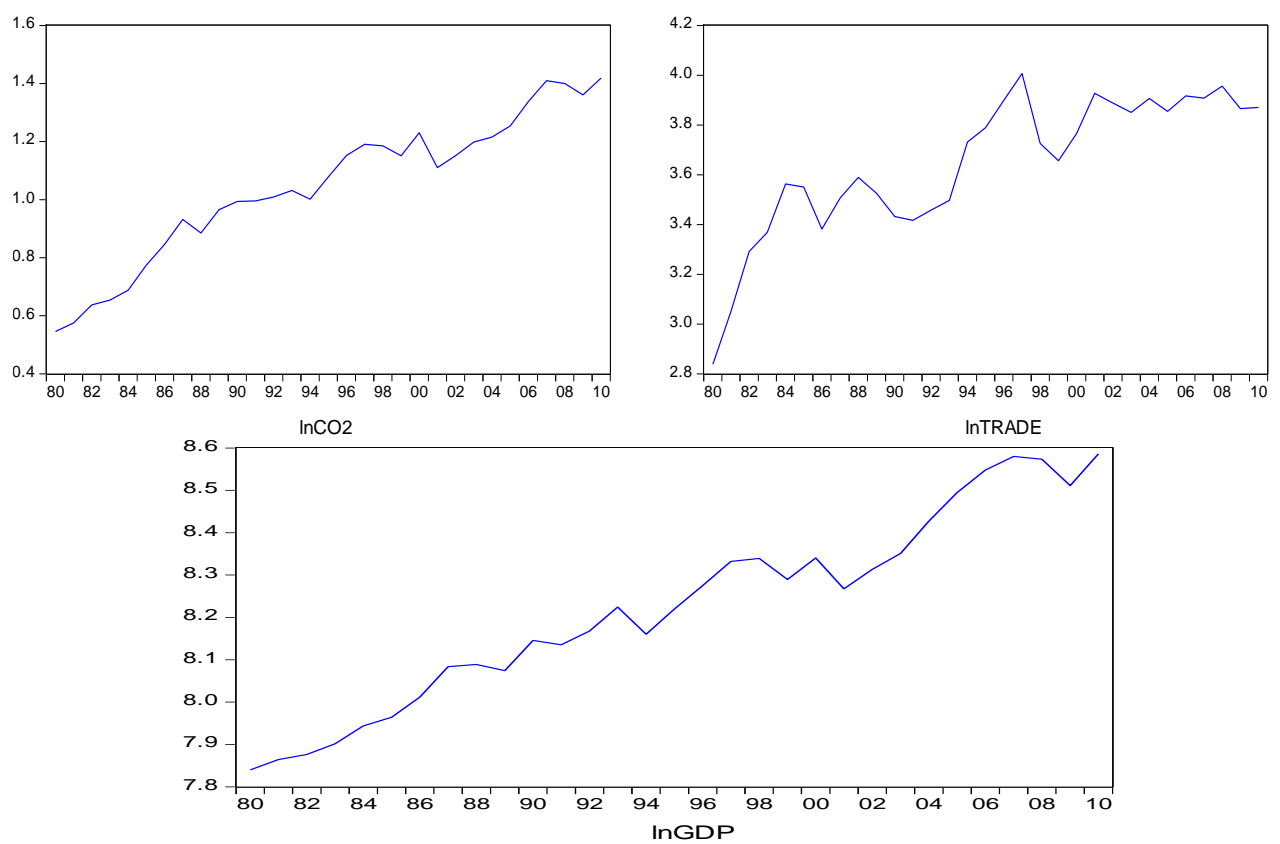

Şekil 1: Serilerin (lnCO2, $\operatorname{lnTRADE}$, lnGDP) Grafiksel Görünümü

\section{Ekonometrik Metodoloji}

Kişi başına gelir ve dış ticaret yoğunluğunun karbon dioksit salınımı üzerindeki etkisini test edebilmek için eşbütünleşme ve nedensellik analizleri kullanılmıştır. Eşbütünleşme tekniğinin uygulanmasında her bir değişkenin bütünleşme derecesinin belirlenmesi gerekmektedir. Bununla birlikte, literatürde değinildiği gibi, birim kök testlerinin gücüne bağlı olarak farklı testlerin farklı bulgular ortaya koyduğu söylenebilir. $\mathrm{Bu}$ problemin çözümünde Pesaran vd., (2001) yeni bir eşbütünleşme metodu geliştirmiştir. $\mathrm{Bu}$ yaklaşım, ARDL yaklaşımı olarak bilinmekte olup ilk olarak Pesaran ve Shin (1995, 1999) tarafindan ortaya konmuştur. Daha sonraları Pesaran vd. (2001) tarafindan geliştirilmiştir. $\mathrm{Bu}$ çalışmada değişkenler arasındaki uzun dönem ilişkisinin 
varlığı Pesaran vd. (2001) tarafindan geliştirilmiş yeni bir metodoloji olan ARDL sınır testi yaklaşımı ile test edilmektedir.

Günümüz çalışmalarının önemli bir kısmı Engle ve Granger (1987), Johansen (1988), Johansen ve Juselius (1990), Stock ve Watson (1993) ile Gregory ve Hansen (1996) tarafindan ele alınan geleneksel eşbütünleşme yaklaşımlarına karşı ARDL sınır testi yaklaşımının tercih edilebilir olduğunu göstermektedir. Nitekim Peseran $v d$. (2001) sınır testinin kullanılmasının üç temel mantığının olduğunu vurgular. Birincisi; Pesaran $v d$. (2001) modelin ARDL derecesinin belirlendiğinde ilişkinin EKK ile tahmin edilebileceğini ortaya koyması nedeniyle düzey ilişkilerinin tahmininde ARDL modelinin kullanılmasını savunmaktadır. İkincisi; sınır testi regresörler olarak I(1) ve I(0) değişkenlerinin bir bileşimine izin vermektedir. Başka bir ifadeyle, ilgili değişkenlerin bütünleşme düzeyi beklendiği gibi aynı olmayabilir. Üçüncü olarak; bu teknik küçük ve sınırlı örnek büyüklüğü için uygun bir özellik taşır. Böylece ARDL tekniği diğer testlere göre önemli avantajları bünyesinde barındırmaktadır.

Sınır testi, kısa ve uzun dönem katsayıları tahmin edilmeden önce uygulanmaktadır. Test sonuçları uygun olduğunda ARDL prosedürü işleyebilir. Sınır testini uygulayabilmek için öncelikle Kısıtsız Hata Düzeltme Modeli kurulmalıdır. 1 no'lu denklem, Kısıtsız Hata Düzeltme Modeli şeklinde aşağıdaki gibi ifade edilebilir:

$$
\begin{aligned}
& \Delta \ln C O_{2}=\alpha_{0}+\sum_{i=1}^{m} \beta_{1 i} \Delta \ln C O_{2 t-i}+\sum_{i=0}^{n} \beta_{2 i} \Delta \ln T R A D E_{t-i}+\sum_{i=0}^{p} \beta_{3 i} \Delta \ln G D P_{t-i} \\
& +\delta_{1} \ln C O_{2 t-1}+\delta_{2} \ln T R A D E_{t-1}+\delta_{3} \ln G D P_{t-1}+\varepsilon_{t}
\end{aligned}
$$

2 no'lu eşitlikte $\alpha, \Delta$ ve $\varepsilon_{t}$ sırasıyla sabit terim, fark operatörü ve beyaz gürültü sürecini taşıyan hata terimini temsil etmektedir. ARDL prosedürü, 2 no'lu eşitliği kullanarak sınır testi yardımıyla eşbütünleşmenin olmadığını kabul eden sıfır hipotezinin test edilmesiyle işlemeye başlar. 2 no'lu eşitliğin regresyonundan sonra ilgili değişkenler arasında bir uzun dönem ilişkisinin olup olmadığını belirlemek için Wald testi (F istatistiği) hesaplanır. Sıfır ve alternatif hipotezler aşağıdaki gibidir:

$H_{0}: \delta_{1}=\delta_{2}=\delta_{3}=0$ (uzun dönem ilişkisi yoktur)

$H_{A}: \delta_{1} \neq \delta_{2} \neq \delta_{3} \neq 0$ (uzun dönemli bir ilişki vardır)

Hesaplanan F istatistikleri Pesaran vd. (2001) Tablo CI(iii) deki kritik değerleri ile karşılaştırılır. Yazarlar $\mathrm{I}(0)$ ve $\mathrm{I}(1)$ 'e göre değişkenlerin olası sınıflandırılmalarını içeren sınırlar sunarlar. Şayet hesaplanan F istatistiği alt sınır değerinden daha küçük ise o zaman sıfır hipotezi reddedilir, böylece değişkenler arasında uzun dönem ilişkisinin olmadığı sonucuna varılır. Diğer taraftan, hesaplanan F istatistiği üst sınır değerinden daha büyük ise bu durumda değişkenler arasında uzun dönem ilişkisinin varlığına karar verilir. Bunların dışında hesaplanan F istatistiği alt ve üst sınır değerlerinin arasında yer alıyorsa bu durumda belirsiz sonuçlar ile karşılaşılabilmektedir. Sınır testi ile değişkenler 
arasında bir uzun dönem ilişkisinin varlığı belirlendikten sonra değişkenlerin uzun dönem katsayılarının tahmin sürecine geçilebilir. (m,n,p) sıra numaralı bir ARDL modeli ARDL katsayılarının belirlenmesi için oluşturulur. 1 no'lu eşitliğe göre uzun dönem ilişkisini temsil eden koşullu bir ARDL (m,n,p) modeli aşağıda yer alan 3 no'lu eşitlik ile gösterilebilir:

$$
\ln C O_{2}=\alpha_{0}+\sum_{i=1}^{m} \alpha_{1 i} \ln C O_{2 t-i}+\sum_{i=0}^{n} \alpha_{2 i} \ln T R A D E_{t-i}+\sum_{i=0}^{p} \alpha_{3 i} \ln G D P_{t-i}+\varepsilon_{t}
$$

3 no’lu eşitliğin değişkenlerine ilişkin açıklamalar yukarıda verilmişti. Bu eşitliğin uzun dönem katsayıları EKK metodu kullanılarak tahmin edilir. Akaike ve Schwarz bilgi kriterlerine uygun gecikmenin belirlenmesinde başvurulabilir. Ayrıca, ARDL modelinin uygunluğu diagnostik ve istikrarlılık testleri ile araştırılır. Diagnostik testler olarak otokorelasyon ve değişen varyans testleri uygulanabilir. ARDL parametrelerinin istikrarlılığı için CUSUM, CUSUM ${ }^{2}$ yada Chow(1960) testlerine bakılabilir. Son olarak, ARDL katsayılarına dayalı Hata Düzeltme Modeli (ECM) tahmin edilir ve böylece kısa dönem dinamikleri elde edilir. ECM modeli aşağıdaki gibi kurulabilir:

$\Delta \ln C O_{2 t}=\alpha_{0}+\sum_{i=1}^{m} \lambda_{1 i} \Delta \ln C O_{2 t-i}+\sum_{i=0}^{n} \lambda_{2 i} \Delta \ln T R A D E_{t-i}+\sum_{i=0}^{p} \lambda_{3 i} \Delta \ln G D P_{t-i}+\lambda_{4} E C M_{t-1}+\varepsilon_{t}$

4 no'lu eşitlikte yer alan değişkenler yukarıda ifade edilmişti. ECM'deki katsayılar modelin kısa dönem katsayılarını temsil eder. Uzun dönem modelinden elde edilen hata teriminin bir gecikmeli değeri $\left(E C M_{t-1}\right)$ k1sa dönemde meydana gelen şoklardan sonra sistemin uzun dönem dengesine uyarlanma hızını gösterir (Fosu \& Joseph, 2006). Hata düzeltme teriminin istatistiki olarak anlamlı olmas1 ve 0 ile -1 arasında bir değer alması beklenir. Böylece, kısa dönem dengesizlikleri giderilmiş olur.

\section{Ampirik Bulgular}

Sahte regresyon problemi ile hata terimlerinin rastgele yürüyüş probleminden korunabilmek için birim kök testleri uygulanmıştır. Burada PhilipsPeron $(\mathrm{PP})^{1}$ ve Dickey-Fuller (DF) $(\mathrm{GLS})^{2}$ birim kök testleri kullanılmıştır. Tablo 2, PP ve DF-GLS test sonuçlarını özetler. Sıfır hipotez değişkenin birim köke sahip olduğu, alternatif hipotez ise birim köke sahip olmadığı şeklindedir. Gecikme uzunluğu Akaike Bilgi Kriterine (AIC) göre belirlenmiştir. DF-GLS test sonuçları serilerin düzeyde durağan olmadığını, birinci farklar alındığında durağanlığın söz konusu olduğunu yani serilerin I(1) olduğunu ortaya

\footnotetext{
${ }^{1}$ Phillips ve Perron (1988) özellikle finansal zaman serilerinin analizinde popüler olan birkaç birim kök testi geliştirmiştir. Bu testler, hata terimlerindeki seri korelasyon ve heteroskedastisity problemlerine bakış açıları itibariyle ADF testlerinden ayrılmaktadır. Phillips-Perron testlerinin ADF testlerine önemli bir üstünlüğ̈, PP testlerinin $u_{t}$ hata terimindeki genel heteroskedastisity formlarına karşı daha dirençli olmasıdır (Hamilton, 1994). Bir diğer avantajı, kullanıcının test regresyonları için spesifik bir gecikme uzunluğuna sahip olmamasıdır. Bu testlerde maksimum gecikme uzunluğu, Newey-West kriteri dikkate alınarak belirlenir (Newey ve West, 1994).

${ }^{2}$ Dickey-Fuller testlerinin gücünün düşük olması nedeniyle Elliott vd., (1996) tarafindan alternatif bir birim kök testi önerilmiştir. Modifiye edilmiş Dickey-Fuller testi olarak da bilinen bu test genelde DF-GLS testi olarak isimlendirilmektedir.
} 
koymaktadır. PP test sonuçlarına göre $\ln \mathrm{CO}_{2}$ ve $\ln G D P$ değişkenleri I(1), $\ln T R A D E$ ise I(0) olarak bulunmuştur. Bu sonuçlar Pesaran vd. (2001) tarafindan önerilen sınır testi yaklaşımının kullanılmasına izin vermektedir.

Tablo 2: PP ve DF (GLS) Test Sonuçları

\begin{tabular}{|c|c|c|c|c|}
\hline \multicolumn{5}{|l|}{ Panel A } \\
\hline \multirow[t]{2}{*}{ Düzey } & \multicolumn{2}{|r|}{ PP } & \multicolumn{2}{|c|}{ DF-GLS } \\
\hline & Sabitli & Sabitli-Trendli & Sabitli & Sabitli-rendli \\
\hline $\ln \mathrm{CO}_{2}$ & $-1.561(3)$ & $-2.459(1)$ & $0.107(0)$ & $-2.325(0)$ \\
\hline $\ln G D P$ & $-0.626(3)$ & $-3.038(1)$ & $0.395(0)$ & $-3.093(0)$ \\
\hline $\ln T R A D E$ & $-3.273^{\mathrm{b}}(2)$ & $-3.574^{b}(5)$ & $-1.198(0)$ & $-2.655(0)$ \\
\hline \multicolumn{5}{|l|}{ Panel B } \\
\hline \multirow[t]{2}{*}{ Birinci Farkları } & \multicolumn{2}{|r|}{$\mathrm{PP}$} & \multicolumn{2}{|c|}{ DF-GLS } \\
\hline & Sabitli & Sabitli-Trendli & Sabitli & Sabitli-Trendli \\
\hline $\ln \mathrm{CO}_{2}$ & $-6.143^{\mathrm{a}}(1)$ & $-6.291^{a}(2)$ & $-6.236^{\mathrm{a}}(0)$ & $-6.403^{a}(0)$ \\
\hline $\ln G D P$ & $-6.188^{a}(3)$ & $-6.070^{\mathrm{a}}(3)$ & $-6.204^{\mathrm{a}}(0)$ & $-6.188^{\mathrm{a}}(0)$ \\
\hline $\ln T R A D E$ & - & - & $-3.848^{a}(0)$ & $-4.644^{\mathrm{a}}(0)$ \\
\hline
\end{tabular}

Not: Parantez içindeki değerler gecikme uzunluğunu gösterir. ${ }^{\mathrm{a}} \mathrm{ve} \mathrm{b}^{\mathrm{b}} \% 1 \mathrm{ve} \% 5$ düzeyinde anlamlllığ ifade eder.

İki adımlı ARDL sınır testi prosedürü, değişkenlerin gecikme uzunluğunun belirlenmesini gerekli kılar. $\mathrm{Bu}$ çalışmada optimal gecikme uzunluğu kriteri minimum AIC değeri dikkate alınarak 3 olarak tespit edilmiștir. $\% 5$ anlamlılık seviyesinde hesaplanan $\mathrm{F}$ istatistiği değeri (6.468) üst kritik sinır (5.85) değerinden büyüktür. Bu durum kişi başına gelir, dış ticaret açıklı̆̆ ve karbon dioksit salınımı arasında bir uzun dönem ilişkisinin varlığını kanıtlamaktadır. Fonksiyonel form, normal dağılım, değişen varyans ve otokorelasyonu içine alan diagnostik testler de modelin uygunluğuna işaret etmektedir (Tablo 3).

Tablo 3: Sınır Testi Sonuçları

\begin{tabular}{|c|c|c|}
\hline Tahmin edilen eşitlik & \multicolumn{2}{|c|}{$\ln C \mathrm{O}_{2}=f(\ln G D P, \ln T R A D E)$} \\
\hline F-istatistiği & \multicolumn{2}{|c|}{$6.468(0.005)$} \\
\hline Optimum gecikme uzunluğu & \multicolumn{2}{|c|}{$[3,3,3]$} \\
\hline \multirow{3}{*}{ Anlamlılık seviyesi } & \multicolumn{2}{|c|}{ Kritik değer } \\
\hline & Alt sinir & Üst sinır \\
\hline & 6.34 & 7.52 \\
\hline $5 \%$ & 4.87 & 5.85 \\
\hline $10 \%$ & 4.19 & 5.06 \\
\hline Diagnostik testler & \multicolumn{2}{|c|}{ İstatistikler } \\
\hline $\mathrm{R}^{2}$ & \multicolumn{2}{|c|}{0.841} \\
\hline Düzeltilmiş- $\mathrm{R}^{2}$ & \multicolumn{2}{|c|}{0.715} \\
\hline F-istatistiği & \multicolumn{2}{|c|}{$6.651(0.000)$} \\
\hline Breusch-Godfrey LM & \multicolumn{2}{|c|}{$1.908(0.187)$} \\
\hline ARCH LM & \multicolumn{2}{|c|}{$0.070(0.793)$} \\
\hline Jarque-Bera normality & \multicolumn{2}{|c|}{$0.893(0.639)$} \\
\hline Ramsey Reset & \multicolumn{2}{|c|}{$0.462(0.524)$} \\
\hline
\end{tabular}

Not: Gecikme uzunluğunun belirlenmesinde AIC kullanılmıştır. Kritik değer sınırları Pesaran vd. (2001) Tablo C1(v)'den alınmıştır. Parantez içindeki rakamlar olasılık değerlerini gösterir. 
Kişi başına gelir, dış ticaret yoğunluğu ve karbon dioksit salınımı arasında bir uzun dönem denge ilişkisinin varlı̆g 1 belirlendikten sonra bu uzun dönem ilişkisini yansıtan parametrelerin tahminine geçilmiştir. EKK tahminlerini yansıtan Tablo 4'ten görüleceği üzere kişi başına gelir ve diş ticaret yoğunluğu değişkenleri karbon dioksit salınımı ile pozitif ilişki içindedir. Karbon dioksit salınımının gelir ve diş ticaret elastikiyeti sırasıyla 1.520 ve 0.265 olarak bulunmuştur. $\mathrm{Bu}$ sonuçlar, ekonomik büyüme ve diş ticaretin söz konusu dönemde Türk ekonomisinde çevre kirliliğini artırdığını ortaya koymaktadır. Tahmin modelinin uygunluğu için diagnostik testlere başvurulmuştur. Tablo 5 'te sunulan diagnostik test sonuçları ARDL modelinde otokorelasyon, değişen varyans ve fonksiyonel form sorunlarının olmadığını ayrıca hataların normal dağılım sergilediğini ortaya koymaktadır.

Tablo 4: ARDL $(0,3,3)$ Modelinin Tahmin Sonuçları

\begin{tabular}{|c|c|c|}
\hline \multirow{2}{*}{ Değişkenler } & \multicolumn{2}{|c|}{ Bağımlı değişken: $\mathbf{l n C \boldsymbol { O } _ { 2 }}$} \\
\cline { 2 - 3 } & Katsayı & $\boldsymbol{t}$-istatistiği \\
\hline $\ln G D P$ & 0.899 & $6.349(0.000)$ \\
\hline $\ln G D P(-1)$ & -0.081 & $-0.532(0.601)$ \\
\hline $\ln G D P(-2)$ & 0.243 & $1.393(0.180)$ \\
\hline $\ln G D P(-3)$ & 0.458 & $2.923(0.009)$ \\
\hline $\ln T R A D E$ & 0.065 & $1.090(0.290)$ \\
\hline $\ln T R A D E(-1)$ & 0.044 & $0.614(0.546)$ \\
\hline $\ln T R A D E(-2)$ & 0.062 & $0.881(0.389)$ \\
\hline $\ln T R A D E(-3)$ & 0.092 & $1.845(0.081)$ \\
\hline CONSTANT & -12.079 & $-7.829(0.000)$ \\
\hline \multicolumn{2}{|c|}{ Diagnostik testler } \\
\hline R ${ }^{2}$ & \multicolumn{2}{|c|}{0.989} \\
\hline Düzeltilmiş-R ${ }^{2}$ & \multicolumn{2}{|c|}{0.984} \\
\hline F-istatistiği & \multicolumn{2}{|c|}{$0.049(0.954(0.000)$} \\
\hline Breusch-Godfrey LM Testi & \multicolumn{2}{|c|}{$0.095(0.759)$} \\
\hline ARCH LM Testi & \multicolumn{2}{|c|}{$0.372(0.830)$} \\
\hline Jarque-Bera normality & \multicolumn{2}{|c|}{$2.618(0.103)$} \\
\hline Ramsey Reset &
\end{tabular}

Not: Parantez içindeki rakamlar olasılık değerlerini gösterir.

Tablo 5: Uzun Dönem Elastikiyetleri

\begin{tabular}{|c|c|c|}
\hline \multicolumn{3}{|c|}{ Uzun Dönem Katsayıları (Bağımlı değişken: $\ln \boldsymbol{C O}_{2}$ ) } \\
\hline Değişken & Katsayı & $t$-istatistiği \\
\hline $\ln G D P$ & 1.520 & $7.908(0.000)$ \\
\hline $\ln T R A D E$ & 0.265 & $3.827(0.000)$ \\
\hline CONSTANT & -12.079 & $-7.829(0.000)$ \\
\hline
\end{tabular}

Not: Parantez içindeki rakamlar olasılık değerlerini gösterir.

Üzerinde durulan bir diğer durum kısa dönem dinamikleriyle birlikte hata düzeltme terimini oluşturmak için kullanılan uzun dönem katsayılarının istikrarlılığı konusudur. Laidler (1993) ve Bahmani-Oskooee (2001)'nin de işaret ettiği gibi, istikrarlılık ile ilişkili problemlerin bir kısmı uzun dönem ilişkisinden hareketle belirlenen kısa dönem dinamiklerinin uygun olmayan şekilde modellenmesinden kaynaklanır. Bir istikrarlılık testine kısa dönem dinamiklerini dâhil etmek uygun olacaktır. Bu bağlamda, burada Brown vd. (1975) tarafından 
önerilen CUSUM ve CUSUM ${ }^{2}$ testleri ile birlikte Chow (1960) testi uygulanmıştır. Şekil 2, CUSUM ve CUSUM ${ }^{2}$ testlerinin grafiğini sunar. CUSUM testine göre ilgili değerlerin kritik sınırlar içinde yer aldığı, CUSUM ${ }^{2}$ testinde ise sadece1999 yılına ilişkin küçük bir taşmanın olduğu görülmektedir. Bu nedenle sonuçları teyit edebilmek için Chow testine de bakılmıştır. Tablo 6'da sunulan test sonucuna göre söz konusu dönemde özellikle de 1999 y1lında herhangi bir yapısal kırılmanın olmadığı söylenebilir. Dolayısıyla uzun dönem parametrelerinin istikrarlı olduğu sonucuna varılmıştır.
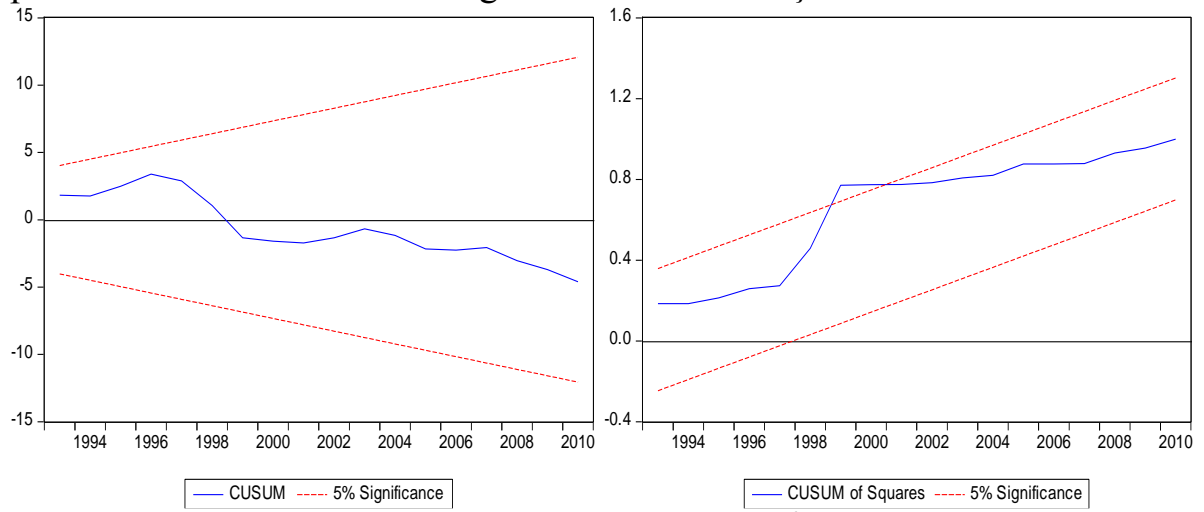

Şekil 2: CUSUM ve CUSUM²Testleri

Tablo 6: Chow Testi Sonuçları

\begin{tabular}{lll}
\hline Kestirim Dönemi & F-istatistiği & Olasılık \\
\hline $1999-2010$ & 0.589 & 0.795
\end{tabular}

Kısa dönem dinamiklerine ilişkin sonuçlar ise Tablo 7'de sunulmuştur. Ampirik kanıtlar, dış ticaret açıklığı ile karbon dioksit salınımı arasında kısa dönemde istatistiki olarak anlamlı bir ilişkinin olmadığına işaret etmektedir. Sonuçlar aynı zamanda uzun dönemde olduğu gibi, kısa dönemde de kişi başına gelir ile karbon dioksit salınımı arasında \%1 anlamlılık seviyesinde pozitif bir ilişkinin olduğunu vurgulamaktadır. Yani, Türkiye ekonomisinde ekonomik büyüme kısa dönemde çevre kirliliğini belirleyen önemli bir unsurdur.

Hata Düzeltme Modeli regresyon sonuçları, diagnostik test istatistikleriyle uyumlu gözükmektedir. Üstelik hata düzeltme katsayısı (ECM-1) negatif ve istatistiki olarak \%1 seviyesinde anlamlı bulunmuştur. Bu durum, değişkenler arasındaki uzun dönemli ilişkinin varlığını bir başka açıdan kanıtlamaktadır. $\mathrm{Bu}$ katsayının tahmin değeri $(-0.876)$ kısa dönem şoklarını takiben uzun dönem dengesinden meydana gelen sapmaların 1 dönem sonrasında $\% 88$ 'inin giderilebildiğini ifade etmektedir. 
Tablo 7: ARDL $(0,3,3)$ Hata Düzeltme Modeli Tahmin Sonuçları

\begin{tabular}{|c|c|c|}
\hline \multicolumn{3}{|c|}{$\begin{array}{c}\text { Hata Düzeltme Modeli Katsayıları } \\
\left.\text { (Bağıml değişken: } \Delta \ln \mathrm{CO}_{2}\right)\end{array}$} \\
\hline Değişken & Katsay1 & $t$-istatistiği \\
\hline$\Delta \ln T R A D E$ & 0.057 & $1.207(0.241)$ \\
\hline$\Delta \ln G D P$ & 0.886 & $8.044(0.000)$ \\
\hline CONSTANT & -0.016 & $-1.963(0.063)$ \\
\hline ECM(-1) & -0.876 & $-5.116(0.000)$ \\
\hline \multicolumn{3}{|c|}{ Diagnostik testler } \\
\hline \multicolumn{2}{|c|}{ R $^{2}$} & 0.821 \\
\hline Düzeltilmiş-R ${ }^{2}$ & 0.759 \\
\hline F-istatistiği & $13.162(0.000)$ \\
\hline Breusch-Godfrey LM Testi & $0.546(0.588)$ \\
\hline ARCH LM Testi & $0.001(0.976)$ \\
\hline Jarque-Bera normality & $0.077(0.962)$ \\
\hline Ramsey Reset & $0.731(0.402)$ \\
\hline
\end{tabular}

\section{Sonuç}

Not: Parantez içindeki rakamlar olasılık değerlerini gösterir.

$\mathrm{Bu}$ çalışmada kişi başına gelir ve diş ticaret açıklığının karbon dioksit salınımı üzerindeki etkisi zaman serisi analizlerinde önemli bir yeri olan eşbütünleşme metodolojisi çerçevesinde incelenmiştir. $\mathrm{Bu}$ amaçla, Türkiye ekonomisine ilişkin 1980-2010 dönemini kapsayan y1llık verilerden oluşan 31 gözlem veri seti oluşturulmuştur. Serilerin birim kök sonuçları genelde birinci farkında durağanlığa işaret etmektedir. Böylece ARDL eşbütünleşme metodu olarak bilinen sınır testi yaklaşımı kullanılarak söz konusu model tahmin edilmiştir. Hesaplanan $\mathrm{F}$ istatistiği üst kritik sınır değerinden büyük olduğu için söz konusu değişkenler arasında uzun dönem denge ilişkisinin varlığına hükmedilmiştir.

ARDL modeli tahmin sonuçları, kişi başına gelir ve dış ticaret açıklığı değişkenlerinin karbondioksit salınımı ile pozitif yönde ilişki içinde olduğunu ve sırasıyla elastikiyetlerin 1.520 ve 0.265 değerlerini aldığını ortaya koymaktadır. Başka bir ifadeyle, söz konusu dönemde ekonomik büyüme ve diş ticaret açıklığ 1 Türkiye ekonomisinde çevre kirliliğini artıran önemli belirleyicilerdir. $\mathrm{Bu}$ sonuçlar Türkiye ekonomisi için ekonomik büyüme ve dış ticaret odaklı kirlilik hipotezlerinin varlığını ampirik olarak kanıtlamaktadır. Diğer taraftan, hata düzeltme modeli bulguları değişkenler arasında istikrarlı uzun dönemli ilişkinin varlığını doğrular niteliktedir. Hata düzeltme katsayısının (-0.876) negatif ve istatistiki olarak anlamlı bulunması bunun önemli bir delilidir. Çalışmanın bulguları Mete vd., (2007)'un panel regresyon tahmin sonuçları ile örtüşmektedir. Ampirik sonuçlar ayrıca, Baek $v d$. (2009) ile yapısal eşitlik modeli üzerinde duran Kukla-Gryz (2009)'nin gelişmekte olan ülke ekonomisi sonuçlarıyla benzerlik taşımaktadır. Diğer taraftan, Dasgupta vd. (2002)'nin ticaret liberalleşmesi ile ilgili bulguları bu çalışmanın bulguları ile uyumluluk arz ederken, Anweiler $v d$. (2001)'in bulguları ile farklılaşmaktadır.

Gelir ve dış ticaret değişkenlerinin karbondioksit salınımı ile uzun dönemli pozitif yönlü ilişkiye sahip olması, Türkiye ekonomisinde karbondioksit 
salınımının azaltılmasına yönelik bir takım önlemlerin alınması gerektiğine işaret eder. Bu doğrultuda politika önerileri şöyle sıralanabilir: a) Piyasa ekonomisi ile uyumlu ve dış rekabet gücünü zayıflatmayacak, aynı zamanda negatif dışsallıkları içselleştirecek "karbon vergisi" ile ilgili yasal düzenlemeler yapılmalı b) Enerji verimliliğini artıracak kredi uygulamaları genişletilerek sürdürülmeli c) Motorlu taşıtlar vergisinde karbondioksit salınım miktarına göre oran farklılaştırmaları uygulanmalı d) Türkiye'de elektrik üretiminin fosil yakıtlara (Kömür, petrol, doğalgaz) bağlılı̆̆ını azaltacak yenilenebilir enerji kaynaklarını teşvik edici yasal düzenlemeler yapılmalı e) Son olarak, Türkiye'nin İklim Değişikliği Ulusal Eylem Planı (2011-2023) çerçevesinde ayrıntılı bir şekilde belirtilen Sera Gazı Emisyon Kontrolü Eylem Planı'nın uygulanması, ekonomik ve siyasi kaygılardan dolay1 geciktirilmemelidir.

\section{KAYNAKÇA}

ANTWEILER W., COPELAND B.R., ve TAYLOR. M.S. (2001), "Is free trade good for the environment?", The American Economic Review, 91(4), 877-908.

ARROW, K., BOLIN, B., COSTANZA, R., DASGUPTA, P., FOLKE, C., HOLling, C. S., JANSSON, B., LEVIN, S., MALER, K., PERRINGS, C., ve PIMENTEL, D. (1995), "Economic growth, carrying capacity and the environment", Science, 268, 520-521.

BAEK, J., CHO, Y., ve KOO, W.W. (2009), "The environmental consequences of globalization: A country-specific time-series analysis". Ecological Economics, 68, 2255-2264.

BAHMANI-OSKOOEE, M. (2001), "How stable is M2 money demand function in japan?”, Japan and the World Economy. 13, 455-461.

BOULATOFF, C. ve JENKINS, M. 2010. "Long-term nexus between openness, income, and environmental quality”, Int. Adv. Econ. Res., 16, 410-418.

BECKERMAN, W. (1974), In Defence of economic growth, London: Jonathan Cape.

BIRDSALL, N., ve WHEELER, D. (1993), "Trade policy and industrial pollution in Latin America: Where are the pollution havens?", Journal of Environment and Development, 2(1), 137150 .

BOULATOFF, C., ve JENKINS, M. (2010), "Long-term nexus between openness, income and environmental quality", International Advances in Economic Research. 16(4), 410-418.

BROWN, R. L., DURBIN, J., ve EVANS, J. M. (1975), "Techniques for testing the constancy of regression relations over time", Journal of Royal Statistical Society. 37 (Series B), 149163.

CHEBBI, H. E., OlARREAGA, M. ve ZITOUNA, H. (2009), "Trade Openness and CO2 Emissions in Tunisia. Shocks vulnerability and therapy", ERF 16th Annual Conference November 7-9, Egypt.

CHOW, G. C. 1960, "Tests of equality between sets of coefficients in two linear regressions", Econometrica, 28, 591-605.

COLE, M.A. (2004), "Trade, the pollution haven hypothesis and the environmental Kuznets curve: examining the linkages", Ecological Economics, 48, 71-81.

COLE, M. A., ELLIOT, R. J. R., ve Fredriksson, P. G. (2004), "Endogenous pollution havens: Does FDI influence environmental regulations?", Working Paper 2004/20, University of Nottingham.

COONDOO, D., ve DINDA, S. (2002), "Causality between income and emissions: A country group-specific econometric analysis”, Ecological Economics, 40 (3), 351-367.

COPELAND, B.R., \& TAYLOR, M.S. (1994), "North-south trade and the environment, Quarterly Journal of Economics", 109(3), 755-787.

COPELAND, B.R., ve TAYLOR, M.S. (1995), "Trade and transboundary pollution. The American Economic Review”, 85(4), 716-737. 
COPELAND, B.R. ve TAYLOR, M.S. (1997), "The trade-induced degradation hypothesis. Resource and Energy Economics", 19, 321-344.

COPELAND, B.R., ve Taylor, M.S. (2001), "International trade and the environment: A framework for analysis", National Bureau of Economic Research Working Paper 8540.

ÇŞB (2011), İklim Değişikliği Ulusal Eylem Planı:2011-2020, Çevre ve Şehircilik Bakanlığı. Erişim Tarihi: 08 Ocak 2013. http://www.tarimreformu.gov.tr/iklim/dosya/idep.pdf

DASGUPTA, S., LAPLANTE, B., Wang, H., ve Wheeler, D. (2002), "Confronting the environmental Kuznets curve", The Journal of Economic Perspectives, 16(1), 147-168.

DE BRUYN, S. M., (1997)", Explaining the environmental Kuznets curve: structural change and international agreements in reducing sulphur emissions", Environment and Development Economics, 2, 485-503.

DE BRUYN, S. M., VAN DER BERGH J.C.J.M., ve OPSCHOOR, J. B. (1998), "Economic growth and emissions: Reconsidering the empirical base of environmental Kuznets curves", Ecological Economics, 25, 161-175.

ELLIOTT, G., ROTHENBERG, T., ve STOCK, J. (1996), "Efficient tests for an autoregressive unit root", Econometrica, 64, 813-836.

EMERSON, J.W., ESTY, D.C., ve HSU, A. (2012), "Environmental performance index and pilot trend environmental performance index", Yale Center for Environmental Law and Policy, Yale University Center for International Earth Science Information Network, Columbia University.

ENGLE, R.F., ve GRANGER, C.W.J. (1987), “Cointegration and error correction: Representation, estimation and testing. Econometrica, 55, 251-76.

EPI (2012), "Environmental performance index: Country profiles", Yale University Erişim Tarihi: 17.05.2013, http://epi.yale.edu/epi2012/countryprofiles

FOSU, O. A. E., ve JOSEPH, M. F. (2006), "Aggregate import demand and expenditure components in Ghana: An econometric analysis", MPRA Paper No.599, August.

GALE, L.R., ve J.A. MENDEZ, (1998), "The empirical relationship between trade, growth and the environment", International Review of Economics and Finance, 7(1), 53-61.

GALEOTTI, M., ve LANZA, A. (1999), "Richer and cleaner? A study on carbon dioxide emissions by developing countries", Energy Policy, 27, 565-573.

GALEOTTI, M., MANERA, M., ve LANZA, A. (2009), "On the robustness of robustness checks of the environmental Kuznets curve hypothesis", Environment and Resources Economics, 42, 551-574.

GILES, D. E., ve MOSK, C. (2003), "Ruminant eructation and a long-run environmental Kuznets curve for enteric methane in New Zealand: Conventional and fuzzy regression", Econometrics Working Paper, Vol. 0306. Canada: Department of Economics, University of Victoria.

GREGORY, A.W., ve HANSEN, B.E. (1996), "Residual based tests for co-integration in models with regime shifts", Journal of Econometrics, 70, 99-126.

GROSSMAN, G. M., ve KRUEGER, A. B. (1991), "Environmental impacts of a North American Free Trade Agreement", Working Paper 3914, National Bureau of Economic Research, Cambridge, MA.

GROSSMAN, G. M., ve KRUEGER, A.B. (1993), "Environmental impacts of a North American Free Trade Agreement”, in The U.S.-Mexico Free Trade Agreement, Peter Garber (Ed.), MIT Press.

GROSSMAN, G. M., ve KRUEGER, A.B. (1995), "Economic growth and the environment", Quarterly Journal of Economics, 110(2): 353-77.

HALICIOĞLU, F. (2009), "An econometric study of $\mathrm{CO}_{2}$ emissions, energy consumption, income and foreign trade in Turkey", Energy Policy, 37, 1156-1164.

HAMILTON, J. (1994), Time series analysis. Princeton University Press, Princeton, NJ.

HE, J. ve PATRICK, R. (2010), "Environmental Kuznets curve for $\mathrm{CO}_{2}$ in Canada. Ecological Economics”, 69, 1083-1093. 
HUNG, M. ve SHAW, D. (2006), Economic growth and the environmental Kuznets curve in Taiwan: A simultaneity model analysis. In M. Boldrin (Eds.), Long-Run Growth and Economic Development From Theory to Empirics, UK, Edward Elgar.

IEA (2011), “ $\mathrm{CO}_{2}$ emissions from fuel combustion”, Erişim Tarihi: 12 Mart 2013, http://www.iea.org/publications/freepublications/publication/name,32870,en.htm

JOHANSEN, S. (1988), "Statistical analysis of cointegration vectors", Journal of Economic Dynamics and Control, 12, 231-4.

JOHANSEN, S., ve JUSELIUS, K. (1990), "Maximum likelihood estimation and inference on cointegration: With application to the demand for money", Oxford Bulletin of Economics and Statistics, 52, 169-210.

KAUFMANN, R. K., DAVIDSDOTTIR, B., Garnham, S., \& Pauly, P. (1998), "The determinants of atmospheric $\mathrm{SO}_{2}$ concentrations: Reconsidering the environmental Kuznets curve”, Ecological Economics, 25(2), 209-220.

KOO, A. Y. C. (1974), "Environmental repercussions and trade theory", Review of Economics and Statistics, 56(2), 235-244.

KUKLA-GRYZ, A. (2009), "Economic growth, international trade and air pollution: A decomposition analysis", Ecological Economics, 68, 1329 - 1339.

LAIDLER, E. W. D. (1993), The Demand for Money: Theories, Evidence and Problems (4th ed.). Harper Collins College Publishers.

LAPAN, H. E. ve SIKDAR, S. (2011), "Strategic environmental policy under free trade with transboundary pollution", Review of Development Economics, 15(1), 1-18.

LOPEZ, R. (1994), "The environment as a factor of production: The effects of economic growth and trade liberalization", Journal of Environmental Economics and Management, 27: 163-184.

LUCAS, R.E.B., WHEELER, D., ve HETTIGE, H. (1992), Economic development, environmental regulation and the international migration of toxic industrial pollution: 1960-88. In P. Low (Eds.), International Trade and the Environment, The World Bank, Washington, DC, pp. 67-88.

MEADOWS, D., ZAHN, E., ve MILLING, P. (1972). The limits to growth. New York: Universe Books.

METE, F. (2007), "Impact of trade liberalization on the environment in developing countries: The case of Nigeria", MPRA Paper, No: 731, November.

MEYER, A.L., VAN KOOTEN, G.C., ve Wang, S. (2003), "Institutional, social and economic roots of reforestation: A cross-country comparison”, International Forestry Review, 5, 29-37.

NEWEY, W.K., ve WEST, K.D. (1994), "Automatic lag selection in covariance matrix estimation", Review of Economic Studies, 61, 631-653.

OECD (2012), OECD Economic survey: Turkey overview. Erişim Tarihi: 12 Mart 2013, www.oecd.org/eco/surveys/OVERVIEW\%20ENGLISH\%20FINAL.pdf

ÖZTÜRK, İ., ve ACARAVCI, A. (2010), “CO2 emissions, energy consumption and economic growth in Turkey", Renewable and Sustainable Energy Reviews, 14, 3220-3225.

PALMER, K.L., ve SIMPSON, D. R. (1993), "Environmental policy as industrial policy", Resources, 112, 17-21.

PANAYOTOU, T. (1993), "Empirical tests and policy analysis of environmental degradation at different stages of economic development", Working Paper WP238, Technology and Employment Programme, Geneva: International Labour Office.

PESARAN, M. H., ve SHIN, Y. (1995), An autoregressive distributed lag modelling approach to cointegration analysis. In S. Strom, A. Holly, A. Diamond (Eds.), Centennial Volume of Ragner Frisch, Cambridge University Press.

PESARAN, M. H., ve SHIN, Y. (1999), “An autoregressive distributed lag modelling approach to cointegration analysis", In S. Strom (Eds.), Econometrics and economic theory in the 20th century: The Ragnar Frisch Centennial Symposium. Cambridge University Press.

PESARAN, H., SHIN, Y. ve SMITH, R. (2001), "Bounds testing approaches to the analysis of level relationships", Journal of Applied Econometrics, 16, 289-326

PHILLIPS, P.C.B., ve PERRON, P. (1988), “Testing for a unit root in time series regressions", Biometrika, 75, 335-346. 
ROCA, J., PADILlA, E., FARRE, M., ve GALLETTO, V. (2001), "Economic growth and atmospheric pollution in Spain: Discussing the environmental Kuznets curve hypothesis", Ecological Economics, 39(1), 85-99.

ROCK, M. (1996), "Pollution intensity of GDP and trade policy: Can the World Bank be wrong?", World Development, 24(3), 471-479.

SABOORI, B. (2012), "An empirical analysis of the Environmental Kuznets Curve for CO2 emissions in Indonesia: The role of energy consumption and foreign trade", International Journal of Economics and Finance, 4(2), 243-251.

SACHS, J., PANATAYOU, T., ve PETERSON, A. (1999), "Developing countries and the control of climate change: A theoretical perspective and policy implications", CAER II Discussion Paper, no. 44. Harvard Institute for International Development, USA: Cambridge, MA.

SCHMALENSEE, R., STOKER, T. M., ve JUDSON, R.A. (1998), "World carbon dioxide emissions: 1950-2050", Review of Economics and Statistics, LXXX, 15-27.

SELDEN, T. M., ve SONG, D. (1994), "Environmental quality and development: Is there a Kuznets curve for air pollution emissions?", Journal of Environmental Economics and Management, 27, 147-162.

SHAFIK, N., ve BANDYOPADHYAY, S. (1992), "Economic growth and environmental quality", Background Paper for the 1992 World Development Report, Washington D.C: The World Bank.

SOYTAS, U., ve SARI, R. (2009), "Energy consumption, economic growth, and carbon emissions: Challenges faced by an EU candidate member", Ecological Economics, 68, 1667-1675.

STERN, D., COMMON, M.S., ve BARBIER, E.B. (1996), "Economic growth and environmental degradation: The environmental Kuznets curve and sustainable development", World Development, 24, 1151-1160.

STOCK, J. H., ve WATSON, M.W. (1993), “A simple estimator of cointegrating vectors in higher order integrated systems", Econometrica, 61(4), 783-820.

SURI, V., ve CHAPMAN, D. (1998), "Economic growth, trade, and energy: Implications for the environmental Kuznets curve", Ecological Economics, 25, 195-208.

TÜIK, (2013), “Seragazi emisyon envanteri: 1990-2011", Türkiye İstatistik Kurumu Haber Bülteni, Say1 13482, Erişim 25 Tarihi: 2013 , http://www.tuik.gov.tr/PreHaberBultenleri.do?id=13482.

VICTOR P. A. (1972), Pollution, economy and environment, London: George Allen and Unwin.

VINCENT, J.R. (1997), "Testing for environmental Kuznets curves within a developing country", Environment and Development Economics, 2, 417-431.

VOLLEBERGH, H., DIJKGRAAF, E., ve MELENBERG, B. (2005), "Environmental Kuznets curves for $\mathrm{CO}_{2}$ : Heterogeneity versus homogeneity", Discussion Paper 25, Tilburg University, Center for Economic Research, Tilburg.

WHEELER, D., ve MARTIN, P. (1992), "Prices, policies and the international diffusion of clean technology: The case of wood pulp production", In P. Low (Eds.), International trade and the environment (pp.197-224), Washington, DC: World Bank. 